\title{
The effect of various conditions on the ultrafiltration process of bisphenol A using nanocomposite membranes modified with carbon nanotubes
}

\author{
Michat Adamczak ${ }^{1, *}$, Gabriela Kamińska ${ }^{1}$, and Jolanta Bohdziewicz $^{1}$ \\ ${ }^{1}$ Silesian University of Technology, Institute of Water and Wastewater Engineering, Konarskiego 18, \\ 44-100 Gliwice, Poland
}

\begin{abstract}
This study presents effect of various conditions on BPA retention during ultrafiltration process. Polyethersulphone was selected as material for membrane preparation, while membranes were prepared with inverse phase method. Single-walled carbon nanotubes functionalized with carboxyl groups were employed for membrane modification. Tests were carried out for one substance - BPA, with use of three differently types of membranes. Presence of carbon nanotubes influences on membrane properties, like porosity, or contact angle of membranes. It was also found that retention of BPA was depended on its concentration, and also $\mathrm{pH}$ of the solution.
\end{abstract}

\section{Introduction}

Ultrafiltration process is applied mostly to remove colloids, bacteria and macromolecules and for micropollutants elimination. Retention of these compounds reaches level of $80 \%$ and is an effect of adsorption on membrane material [1] Special attention is focused on nanocomposite membrane. It is a new type of UF membrane containing nanoparticles resulting in formation of structure and surface with better properties than conventional ultrafiltration membrane. Many authors suggest that nanocomposite membranes have better antifouling properties and combination of transport - retention characteristic [2].

Tests were carried with use of nanocomposite membranes consisting of polyethersulfone and carbon nanotubes modified with carboxyl groups. In general, carbon nanotubes gained much more attention as nanocomposites in membrane production during last years. Their presence in membrane structure causes desirable effects, like: growth of tensile strength and permeability with retention upkeep or growth. Furthermore, much more advantages were mentioned, like high heavy metals and organic pollutants absorption. As restrictions examples were given a low dispersion level of this material in aqueous solutions [3].

Organic micropollutant - bisphenol A (BPA) - belongs to the group of xenoestrogens, that influence on living organisms and environment. High attention is focused on BPA due to its impact on endocrine system by modification of production, metabolism and transport of hormones. Even very low dose of BPA may cause fertility disruptions, damages in nervous

${ }^{*}$ Corresponding author: michal.adamczak@polsl.pl 
system, reduced immunity, uterine cancer, breast cancer or prostate cancer. BPA penetrates human organisms and environment as a result of massive production and use of plastic solidificated by BPA itself. This substance migrate to groceries from plastic packaging and aluminium cans covered inside by an epoxy resin. In the environment this compound appears by common usage of varnishes and paints with this compound in composition and also by excretion in unmetabolised form to sewage system. In this case BPA get through sewage treatment plant and then into water environment. Presence of this compound in water creates necessity of its removal [4, 5]. Our previous study showed that ultrafiltration with nanocomposite membranes has a potential to remove micropollutants. This study presents results of BPA removal in ultrafiltration process. Filtration was carried out under different conditions.

\section{Materials and methods}

\subsection{Materials}

Single-walled carbon nanotubes functionalized with carboxyl groups (SWCNT-COOH) were obtained from Chengdu Organic Chemicals Co. Ltd., Chinese Academy of Sciences and used for membrane modification. Polyethersulfone (PES) as the basic material for membrane preparation was supplied by BASF Company (Ludwigshafen, Germany). N,Ndimethylformamide (DMF), methanol and acetonitrile (ACN) for HPLC, (all analytically pure) were purchased from Avantor Performance Materials (Central Valley, Pennsylvania, USA). Hydrochloric acid and sodium hydroxide for $\mathrm{pH}$ modification were purchased by Avantor Performance Materials Poland S.A. Deionised water was taken from Milli-Q water purification system (Millipore LLC, Poland).

\subsection{Micropollutants and feed water}

Bisphenol A (BPA) was purchased from Sigma-Aldrich (Poland) in analytical purity grade. The stock solutions of BPA was prepared with methanol $(1 \mathrm{~g} / \mathrm{L})$. The feed solution for retention tests was prepared by diluting the stock solution with deionised water to concentration $0.5 \mathrm{mg} / \mathrm{L}$. $\mathrm{pH}$ of feed solution was adjusted to $4.5,6.5$ or 8.5 using $0.1 \mathrm{M} \mathrm{NaOH}$ and $0.1 \mathrm{M} \mathrm{HCl}$. Concentration of BPA in feed and permeate was determined by SPE (solid phase extraction) and high-performance liquid chromatography (HPLC). For SPE, plastic columns filled with $\mathrm{C} 18$ phase (Supelco) were used. At first C18 cartridges were washed with $5 \mathrm{ml}$ of acetonitrile, $5 \mathrm{ml}$ of methanol and $5 \mathrm{ml}$ of deionised water. After this, $20 \mathrm{~mL}$ of sample was passed through columns. Then, column was completely dried, cartridges were flushed with ACN/methanol (60/40) solution. Eluted portion was analysed using HPLC at a wavelength $220 \mathrm{~nm}$. Chromatograph was equipped with chromatographic column and $\mathrm{UV}$-vis detector. Mobile phase contained $95 \%$ of ACN and $5 \%$ of deionised water. Retention of bisphenol A was calculated according to the following equation:

$$
R=\frac{C_{f}-C_{p}}{C_{f}} \cdot 100 \%
$$

where $R$ is removal degree [\%], $C_{f}$ and $C_{\mathrm{p}}$ are concentrations of micropollutants in feed and permeate water respectively $[\mathrm{mg} / \mathrm{L}]$. 


\subsection{Membrane preparation}

Membranes were prepared by phase inversion method. Casting solution consisted of $15 \mathrm{wt} . \%$ of PES and less than 85 wt.\% of DMF. Content of SWCNT-COOH in solutions was kept at 0.02 wt. $\%$ and 0.5 wt.\%. Exact contribution of CNTs and PES in casting solutions was presented in Table 1. Proper amount of CNTs and PES was added to the solvent (DMF). Casting solution was shaken for $20 \mathrm{~h}$ to obtain homogeneous solution. After that, membranes were cast using doctor blade with $0.2 \mathrm{~mm}$ thickness on glass plate and immediately immersed in deionised water at $\pm 20^{\circ} \mathrm{C}$. Precipitated membranes were stored in deionised water at temperature $7^{\circ} \mathrm{C}$ for $24 \mathrm{~h}$ for their stabilisation.

Table 1. Contribution of ingredients in casting solution.

\begin{tabular}{|c|c|c|c|}
\hline Symbol & PES (wt\%) & CNTs contribution (wt\%) & DMF (wt\%) \\
\hline PES 15 "pristine" & 15 & - & 85.00 \\
\hline PES 15 0.02 & 15 & 0.02 & 84.98 \\
\hline PES 15 0.5 & 15 & 0.5 & 84.50 \\
\hline
\end{tabular}

\subsection{Measurement of contact angle}

Measurements of contact angle (CA) were performed using the goniometer (Pocket Goniometer PG-1) and the sessile drop method was applied. 10 stripes of dried tested membrane was inserted into device. By syringe on top drop of distilled water were applied on membrane surface. Through enlarged projection of water drop on gauge, value of CA was measured. For every type of membrane 10 samples were analysed and average value was calculated.

\subsection{Measurement of porosity}

Sheet of membrane with calculated surface area was dried by paper towel, then weighted in wet state. After this, the same membrane was dried in an oven in $60^{\circ} \mathrm{C}$ for $24 \mathrm{~h}$ and then weighted in dry state. Five sheets of each membrane were used for this measurement. Equation for a calculation of the membrane porosity is as following:

$$
\varepsilon=\frac{m_{w}-m_{d}}{A \cdot L \cdot \rho} \cdot 100 \%
$$

where $\varepsilon$ is porosity [\%], $m_{w}$ is weight of wet membrane $[\mathrm{g}], m_{\mathrm{d}}$ is weight of dry membrane [g]; $A$ is area of membrane $\left[\mathrm{cm}^{2}\right], L$ is membrane thickness [cm] and $\rho$ is pure water density $\left(0.998 \mathrm{~g} / \mathrm{mL}\right.$ in $\left.20^{\circ} \mathrm{C}\right)$.

\subsection{Setup and filtration run}

Retention tests were carried out in dead-end ultrafiltration setup consisted of bottle of nitrogen gas, pressure reducer, filtration cell and volume measuring system. Membranes had an area $38.5 \mathrm{~cm}^{2}$.

Ultrafiltration was carried out for all membranes at $0.075 \mathrm{MPa}$ and in room temperature $\left(20^{\circ} \mathrm{C}\right)$. Experiment included two stages: (1) membrane conditioning with deionized water, (2) retention tests with feed water. All stages were conducted in the same conditions i.e. transmembrane pressure, temperature and velocity. Flux was measured after each 10 minutes of filtration and calculated from the following equation:

$$
J_{V}=\frac{V}{A \cdot t}
$$


where $J_{V}$ is flux $\left[\mathrm{L} \cdot \mathrm{m}^{-2} \cdot \mathrm{h}^{-1}\right], V$ is permeation volume [L], $A$ is membrane effective area $\left[\mathrm{m}^{2}\right]$, and $t$ is permeation time [h].

\section{Results and discussion}

\subsection{Membrane characterization}

As seen in Figure 1, contact angle of membranes was relatively stable and had values from $60.3^{\circ}$ for PES 150.5 to $63.3^{\circ}$ for PES 15 0.02. This similar values correspond to moderate hydrophobic-hydrophilic properties. The lowest contact angle had membrane PES 150.5 , which has simultaneously the highest permeability, confirming slightly better hydrophilic properties. It seems to be clear that higher concentration of SWCNT-COOH increased the hydrophilicity of the PES 150.5 membrane.

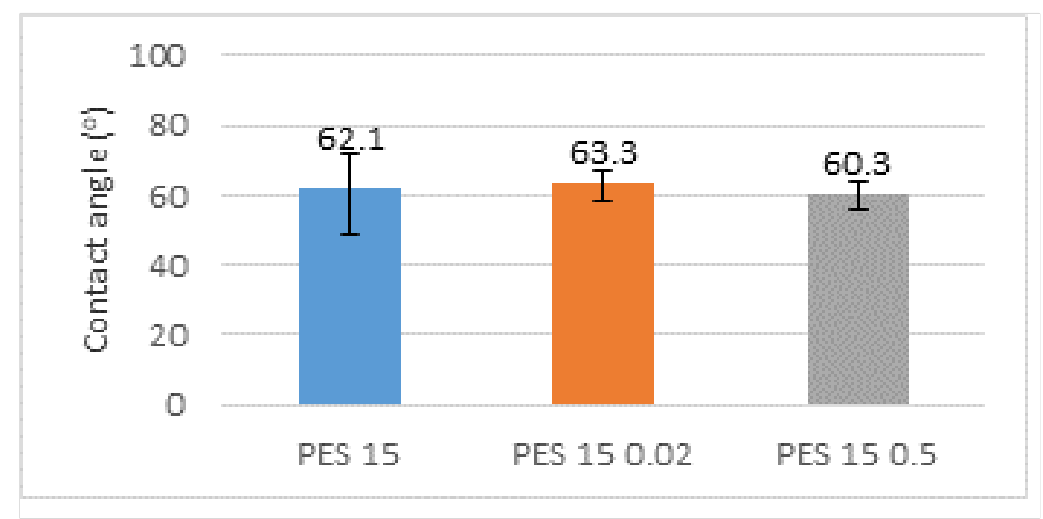

Fig.1. Water contact angle of prepared membranes.

Apart from contact value, presence of CNTs significantly influenced on the porosity of membranes, as seen on Fig. 2. With increased in share of carbon nanotubes, porosity of membranes significanly decreased. Pristine membrane PES 15 had porosity level of $55.2 \%$. Porosity of PES 150.02 decreased significanly to $30.84 \%$ and for PES 150.5 decreased even more to $25.74 \%$ This effect is difficult to explain, because higher concentration of nanocomposites should lead to higher porosity of membrane. However, carbon nanotubes may interacted with polymer that led to lower porosity of membrane. Majeed et.al. [6] explained this phenomen by the delayed exchange between solvent and non-solvent during membrane formation. This occurence was casued by growth of casting solution visciosity due high CNTs concentration [6]. 


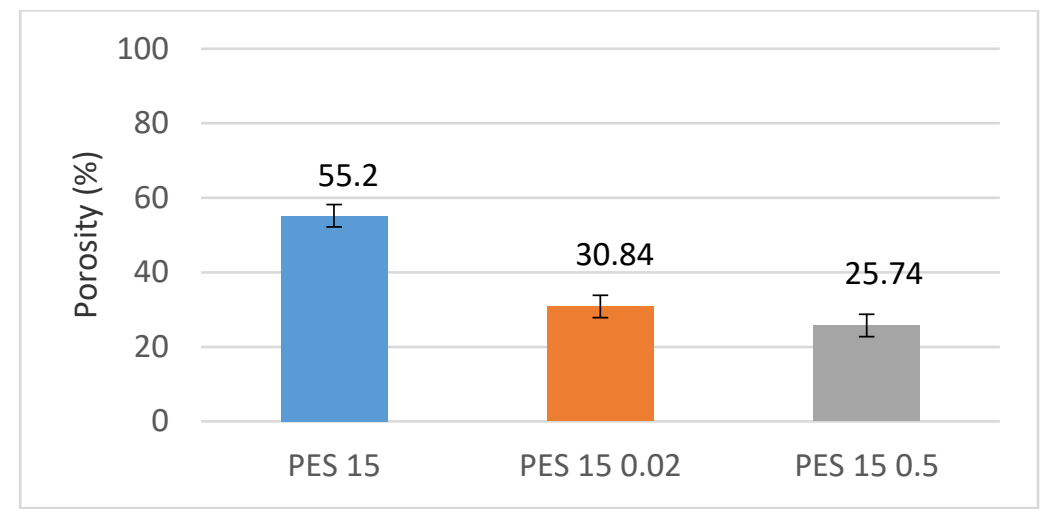

Fig. 2. Measured porosity of prepared membranes.

\subsection{BPA removal}

Figure 3 illustrates the changes in BPA removal and permeate fluxes depending on content of CNTs in membranes and initial BPA concentration in feed in comparison to pristine membrane PES 15. It seems clear that filling of PES membranes with CNTs is favourable to improve their retention performance. Retention of BPA on pristine PES 15 was negligible (25.9\%) in comparison to other membranes with retention between $72 \%$ to $83 \%$. Much higher retention of BPA was a result of high ability to adsorption of this compound on membrane surface. Membranes with the highest content of CNTs retained slightly more contaminants, but as seen on Fig 4 with decrease of permeate flux. Membrane contained $0.5 \mathrm{wt} \%$ of CNTs was tighter and had lower flux. It suggests longer contact time between feed and membrane which results in higher adsorption of BPA. Looser and more porous structure of PES 150.02 causes that the flow of feed through the membrane was faster and mentioned contact time was too short. In other words filling of membrane by SWCNT-COOH was favourable only in certain range. In study of Kamińska et. al [2] it was connected with higher porosity and more open structure. In this work membranes unexpectedly behaved differently. Achieved lower porosity resulted tighter membrane and in effect higher retention and lower flux.

Figure 3 shows that retention of BPA slightly decreased with increase in initial concentration in feed. It is opposite to former tests, because higher concentration should cause also higher retention of this compound. Perhaps alkaline $\mathrm{pH}$ of feed resulted strong repulsion between weak acid compound like BPA and membrane surface, weakened in higher concentration by creation of filter cake layer. 


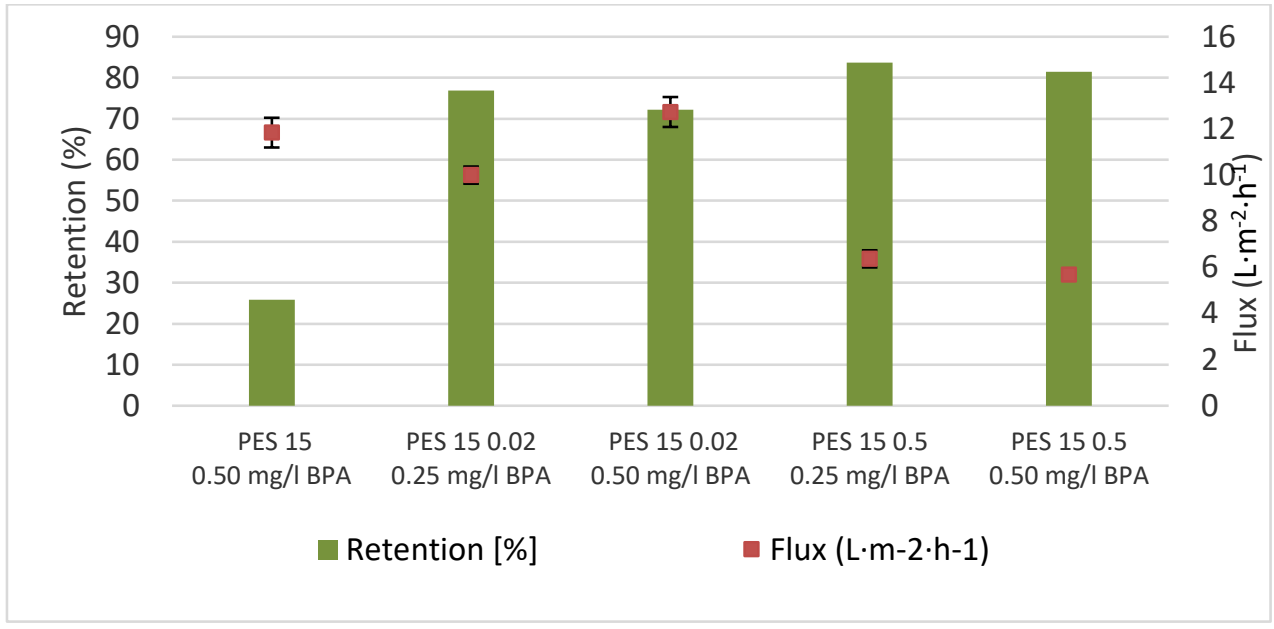

Fig. 3. Retention of BPA depending on concentration of CNTs in membrane structure and initial concentration of BPA in feed.

\subsection{1 $\mathrm{pH}$ influence}

The $\mathrm{pH}$ of feed water affects the retention performance because of its impact on the surface properties of membrane, stability and chemical structure of BPA. $\mathrm{pH}$ has an impact on the chemical form of carboxyl group (Fig. 4). Retention of BPA varied depending on $\mathrm{pH}$ of feed [2]. The slightly lower retention at $\mathrm{pH} 4.5$ arose from the incomplete solubility of BPA in an acid medium. At low and neutral pH BPA is uncharged. The highest retention of BPA was obtained at neutral $\mathrm{pH}$ as an effect of the most intensive adsorption. Interestingly at alkaline $\mathrm{pH}$ retention of BPA was slightly reduced. In higher $\mathrm{pH}$ BPA molecule lose its proton and become negatively charged. Repulsion between negatively charged membrane and deprotonated BPA blocks the adsorption. Then the BPA can block the membrane pores and reducing the retention. Pore size of the membranes will be the main factor in determining the retention. The same conclusions were drawn in work $\mathrm{Wu}$ and others [7] where on polymer membranes modified with carbon nanotubes retention of BPA was tested. In this article three types of membranes were tested: pristine, and two modified with different types of CNTs. $\mathrm{pH}$ increase caused smaller differences between retention of these membranes. In alkaline pH tested membranes were almost similar for retention [7]. Similar but weakened trend is visibile on figure 4. 


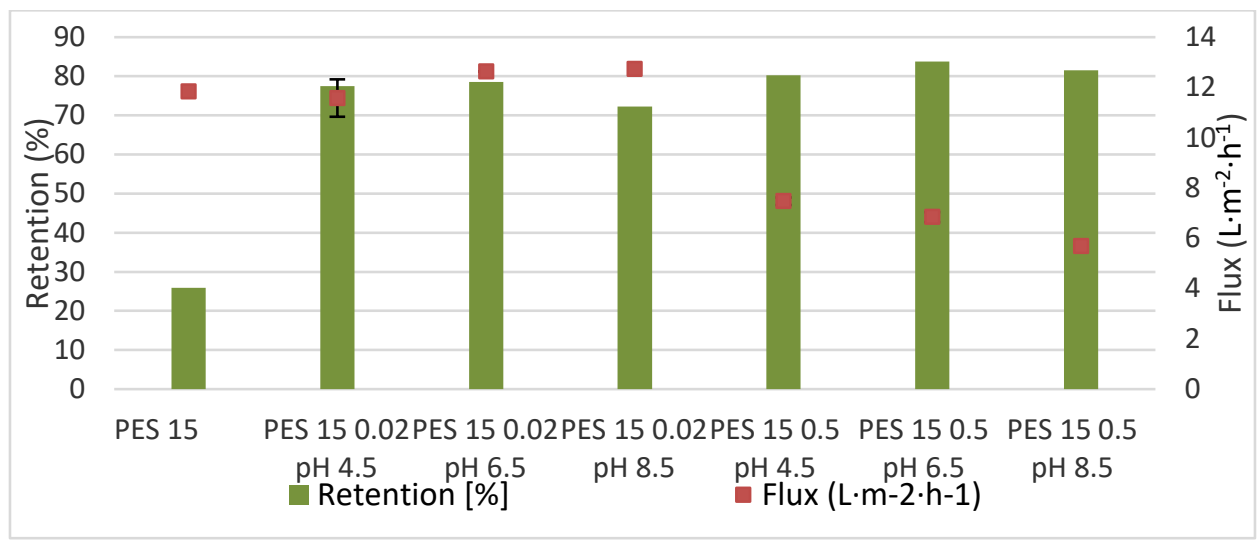

Fig. 4. Retention of BPA depending on $\mathrm{pH}$ of feed.

\section{Conclusions}

Nanocomposite PES membranes were prepared with phase inversion method by introduction of SWCNT-COOH to the casting solution at two different concentrations: $0.02 \mathrm{wt} . \%$ and $5 \mathrm{wt} . \%$. Presence of this modifier highly influenced on porosity value of modified membranes and retention efficiency.

Obviously, removal of tested contaminant was definitely higher for PES 150.02 and PES 150.5 than for pristine membrane PES 15. Increase the SWNCT-COOH content from $0.02 \mathrm{wt} . \%$ to $0.5 \mathrm{wt} . \%$ slightly improved retention of tested compound but with almost $50 \%$ decrease of flux value. The retention effect was related to adsorption of micropollutants in membrane material, therefore nanocomposite membrane with higher adsorption potential was more effective in the removal of micropollutants. Membrane modified with higher CNTs amount had better antifouling properties due to lower porosity. This article confirmed desirable influence of nanotubes on retention of micropollutants, but more tests are needed to obtain more satisfying results.

This work was performed with financial support from the National Science Centre, Poland under grant No. UMO-2016/21/B/ST8/03128.

\section{References}

1. M. Dudziak, Environ. Prot. Eng. 38, 5-17 (2012)

2. G. Kamińska, J. Bohdziewicz, J.I. Calvo, P. Pradanos, A. Hernandez, J. Mem. Sci. 493, 66-79 (2015)

3. A. Rahimpour, M. Jahanshahi, S. Khalili, A. Mollahosseini, A. Zirepour, B. Rajaeian, J. Mem. Sci. 286, 99-107 (2012)

4. M. Dudziak, E. Burdzik, E. Kudlek-Jelonek, Interdyscyplinarne Zagadnienia w Inżynierii $i$ Ochronie Środowiska, 212-219 (Oficyna Wydawnicza Politechniki Wrocławskiej, Wrocław, 2014)

5. D. Łaszczyca, K Paradowska, K. Makarova, Biul. Wydz. Farm. WUM 1, 1-5 (2015)

6. S. Majeed, D. Fierro, K. Buhr, J. Wind, B. Du, A. Boschetti-de-Fierro, V. Abetz, J. Mem. Sci. 403, 101-109 (2012)

7. H. Wu, X. Niu, J. Yang, C. Wang, M. Lu, Chem. Eng. J. 194, 410-416 (2016) 